\title{
IgE-Mediated Food Allergy: Current Management
}

\author{
Rachel G. Robison • Melanie M. Makhija • \\ Jacqueline A. Pongracic
}

Published online: 11 March 2014

(C) Springer Science + Business Media New York 2014

\begin{abstract}
Food allergy affects 4-8 \% of children, and it appears to be increasingly common. The prevalence of peanut allergy has increased in the US and internationally. Pediatricians are on the front lines of providing patient care, so disseminating guidelines and current information regarding appropriate evaluation and principles of management to them is critically important. The approach to the patient with suspected food allergy requires a detailed medical history. In vitro testing is widely available but should be ordered judiciously. Using the history to guide testing can help avoid potential pitfalls of food allergy testing, which is characterized by high false-positive rates. Component-resolved diagnostics represent a new and emerging area. Currently, this modality is most useful for peanut allergy, though further study regarding interpretation of these tests is needed. Management involves complete dietary restriction in most cases, but because accidental reactions do occur, education and emergency preparedness to treat reactions are also essential.
\end{abstract}

Keywords Food · Allergy · Allergen-specific IgE · Foodinduced anaphylaxis - Diagnosis - Disease management

R. G. Robison $(\varangle) \cdot$ M. M. Makhija · J. A. Pongracic Department of Pediatrics, Division of Allergy/Immunology, Ann and Robert H Lurie Children's Hospital of Chicago, 225 E Chicago Avenue, Box 60, Chicago, IL 60610, USA e-mail: rrobison@luriechildrens.org

M. M. Makhija

e-mail: mmakhija@luriechildrens.org

J. A. Pongracic

e-mail: jpongracic@luriechildrens.org

\section{Introduction}

Food allergy (FA) in children has become a commonly encountered diagnosis in a variety of health care settings, both inpatient and outpatient. Community-based physicians, particularly those in pediatrics where the prevalence is highest, need to be knowledgeable in the recognition and management of food-induced allergic reactions. Moreover, pediatricians are most likely to be the first providers from whom patients seek evaluation. Recently, the National Institutes of Health published comprehensive guidelines for the diagnosis and management of food allergy that provided an evidence-based approach for clinicians $[1 \cdot \bullet]$. In this article, we review current approaches to the evaluation and management of food allergy in children. The importance of medical history and the role of in vitro testing are discussed. In addition, new developments that have emerged in the area of in vitro testing for food allergy are also described. Recommendations for preventing reactions, acute treatment strategies in the event of a reaction and long-term management are also discussed.

\section{Diagnosis}

Diagnosis of IgE-mediated food allergy involves medical history, examination, testing and may also include oral food challenges.

A detailed medical history and physical examination can help focus diagnostic testing and can help elucidate the potential causative foods as well as the nature of a reaction. Medical history should include symptoms, which foods were ingested prior to onset of symptoms, when the symptoms occurred, whether the food was previously eaten without reaction and which treatments were given. 
Co-morbid conditions, such as asthma, should also be assessed. There are no pathognomonic symptoms for food allergy. Symptoms of IgE-mediated FA may include cutaneous symptoms (urticaria, angioedema, worsening eczema, erythema, pruritus), GI symptoms (pain, vomiting, diarrhea), respiratory symptoms (cough, throat or chest tightness, wheeze) and cardiovascular symptoms (tachycardia, hypotension, lightheadedness or loss of consciousness). Symptoms generally occur within minutes to $2 \mathrm{~h}$ of ingestion. There is a low positive predictive value of selfreported symptoms of food allergy, and history in itself is not diagnostic [1••]. Physical examinations can be helpful at the time of reaction and may also be helpful in establishing the presence of other atopic conditions in a patient.

\section{Testing}

Skin prick tests (SPTs) are used to identify foods that may be causing IgE-mediated reactions. SPTs detect the presence of allergen-specific IgE (sIgE), which reflects allergic sensitization. Caution must be taken in interpreting results as patients may have $\operatorname{sgE}$ without having clinical food allergy. Compared with oral food challenges, SPTs have a low specificity and low positive predictive value for making a diagnosis. Skin prick testing can lead to overdiagnosis if performed without a clear clinical history. Skin prick testing is performed by placing a drop of allergen solution on the skin and introducing it into the epidermis. A reaction (wheal and erythema) is read 15-20 min after placement. Positive (histamine) and negative (saline) controls are used to validate the tests and control for use of antihistamines or dermatographism [2]. A positive test is considered a wheal with a diameter of $3 \mathrm{~mm}$ or greater than the negative control. While SPTs are commonly used by allergists, this procedure is not conducive to a busy primary care practice.

Direct quantification of allergen-specific serum IgEs may also be used to help identify foods causing reactions and are widely available in the community. As with skin prick testing, sensitization does not always correlate with clinical reactivity. Serum sIgE testing is performed using fluorescence enzyme-labeled assays. This form of testing is more sensitive than the previously used radioallergosorbent test (RAST) [1・•]. There are different laboratory systems that measure sIgE, and the results provided by the different testing laboratories may differ and may not be comparable [3]. Studies have assessed sIgE levels and compared them to oral food challenges. These studies have found that higher SIgE levels correlate with increased probability of allergic reaction with ingestion of the foods. However, the predictive values vary between studies. [1••, 4-7] Of note, sIgE levels do not correlate with reaction severity. Specific
IgE testing may also be useful in cases when skin testing cannot be performed such as atopic dermatitis or inability to withhold antihistamines. Screening panels should not be performed as they can lead to excessive and unnecessary dietary restriction.

The gold standard for diagnosis of IgE-mediated FA is the double-blind placebo-controlled oral food challenge (DBPCFC). A single blind or open food challenge is less time consuming and may also be diagnostic if the challenge is negative or if objective symptoms occur. Food challenges must be performed in a controlled setting by individuals who are trained in the management of anaphylaxis, with emergency medications available. Because of the risk of life-threatening anaphylaxis during a challenge, the procedure should not be performed in patients who have recently had a life-threatening reaction to a food $[1 \bullet \bullet]$.

There are several tests used for allergy that are not recommended for IgE-mediated food allergy diagnosis including intradermal testing, total serum $\operatorname{IgE}$ and atopy patch testing. Other non-standardized tests, including basophil histamine release/activation, other allergen-specific antibodies $\left(\mathrm{IgG}, \mathrm{IgG}_{4}\right)$ and electrodermal tests, have not been found to be useful and are also not recommended.

Component-resolved diagnostics (CRD) refers to the detection of $\operatorname{IgE}$ antibody against particular individual component allergens in an allergen mixture. Allergen CRD is becoming increasingly popular in IgE-mediated FA. CRD has been most widely studied for peanut allergy. IgE against peanut proteins Ara h 1, Ara h 2 and Ara h 3 are associated with severe reactions whereas $\operatorname{IgE}$ to Ara $\mathrm{h} 8$, a molecule similar to a major allergen in birch pollen, is associated with mild symptoms [8-10]. A multicenter study of 167 patients suggests that IgE to Ara $\mathrm{h} 2$ is more specific and has a higher positive predictive value for challenge proven peanut allergy than $\operatorname{sIgE}$ to peanut, although $\operatorname{sIgE}$ to peanut was more sensitive [11•]. Caution must be taken in using CRD as sensitization differs in different populations and geographic locations. While CRD may be a useful adjunct to existing forms of testing for peanut allergy, it is not widely available and should not replace current standard methods of testing.

\section{Short- and Long-Term Management}

\section{Acute Reactions}

There are currently no approved medications or therapies to prevent IgE-mediated reactions to foods, and foods remain the most common reported trigger of anaphylaxis in children and teenagers [12•, 13]. Mild, less severe foodallergic reactions are often managed with dosing of antihistamines and observation. H1-receptor antagonists can 
relieve mild cutaneous symptoms such as pruritus, hives and mild angioedema. Severe, life-threatening allergic reactions (i.e., anaphylaxis) require rapid intramuscular injection of epinephrine. Prompt administration of epinephrine is the first-line treatment for anaphylaxis, and delay in use has been associated with fatal and biphasic anaphylaxis [12•]. H1-receptor antagonists are not a substitute for epinephrine as they cannot aid in upper airway obstruction, hypotension or shock [12•]. However, studies find that epinephrine is not always utilized when indicated. In one review of over 2,000 patients in a European anaphylaxis registry, fewer than one in six $(13 \%)$ of patients received epinephrine, whereas $50 \%$ received antihistamines and $51 \%$ received corticosteroids in severe anaphylactic reactions [14].

After use of epinephrine for food-induced anaphylaxis, the emergency response system should be activated. The patient may be placed in a supine or recumbent position with their legs elevated to increase central perfusion. Adjunctive medications such as H1- and H2-receptor antagonists may be given. An inhaled bronchodilator may also be used for relief of wheezing, cough and bronchospasm, but is not a substitute for epinephrine during anaphylaxis. For persistent symptoms, one can repeat epinephrine dosing every $5 \mathrm{~min}$ if necessary; this need is not uncommon. In a referral population of children and adolescents with multiple food allergies, $19 \%$ of foodinduced anaphylaxis episodes were treated with a second dose of epinephrine, and $6 \%$ of anaphylactic reactions were given a third dose [15].

Other adjunctive measures such as supplemental oxygen and intravenous fluids may be considered once epinephrine has been given. Recurrence of symptoms, also referred to as a biphasic reaction, has been reported in $6 \%$ of all anaphylactic reactions affecting children regardless of trigger or $1-20 \%$ of all episodes of anaphylaxis. [16, 17] However, the onset of this symptom recurrence is variable, occurring 1-78 $\mathrm{h}$ after resolution of the initial reaction with the majority taking place within $8 \mathrm{~h}$ [17]. Due to this risk, the National Institute of Allergy and Infectious Diseases (NIAID) guidelines recommend observation post-anaphylaxis for a $4-6 \mathrm{~h}$ period in a medical setting [1・•]. Though the efficacy of systemic corticosteroids in anaphylaxis has not been well established, they are often administered for a 2-3-day course for of prevention of biphasic or protracted reactions $[1 \bullet \bullet, 18]$.

\section{Long-Term Management}

After confirmation of the diagnosis of food allergy and identification of relevant allergens, strict avoidance of the allergenic food is recommended. Unfortunately, accidental ingestions do occur because of hidden allergens, contamination and human error. In a prospective observational cohort, $87.4 \%$ of reactions to milk, egg or peanut were due to accidental exposures, with parents being the most common caregiver at the time of exposure. In this study, $52.5 \%$ of participants reported more than one accidental reaction over a median follow-up period of 36 months [19]. Studies of accidental exposure in peanutallergic children note a $12.5 \%$ rate of reaction annually with only $39.5 \%$ of exposures occurring in the child's own home [20]. Patients and parents must receive education on reading food labels and identifying allergenic ingredients. Though the US has labeling laws in effect for the top eight food allergens when present as ingredients (under the Food Allergen Labeling and Consumer Protection Act or FAL$\mathrm{CPA}$ ), use of shared equipment and processing with allergens is reported voluntarily at the discretion of manufacturers in advisory statements or labels. One study of a convenience sample of supermarket products containing peanut advisory statements found that $4.5 \%$ of items tested contained detectable peanut, while $2-3 \%$ of a representative sample of packaged foods without any advisory label contained detectable amounts of milk or egg [21]. Findings such as these underscore the need for added vigilance in food-allergic patients when buying processed foods.

Acute management plans, also termed emergency care or action plans, are provided to patients and parents to instruct them on recognition and recommended treatment of acute reactions. Provision and review of the acute management plan by physicians or other knowledgeable health care providers is necessary to ensure that families are prepared to treat any potential reactions. It must be reinforced that the severity of future reactions cannot be predicted by blood or skin testing or by past reaction severity [1••]. Epinephrine auto-injectors should be on hand so that epinephrine can be given as soon as possible, and caregivers (and patients when of appropriate age) should be instructed in proper use. Previous studies using older auto-injector devices have shown relatively low rates of parents $(38 \%)$, pediatricians $(21 \%)$ and residents (36\%) able to demonstrate proper auto-injector use [22]. In a more recent study at a follow-up allergist visit of 141 parents who had previously received training on proper use at a preceding visit, $38 \%$ failed to remove the cap, and $62-87 \%$ failed to perform the last two steps of holding the device in place for $10 \mathrm{~s}$ followed by massaging the injection site [23]. Newer injectors including the Auvi-Q device (Intelliject Inc., Richmond, VA; Allerject in Canada; Auvi$\mathrm{Q}$ and Allerject are registered trademarks of Sanofi US LLC, Bridgewater, NJ) were designed with the intention for easy portability along with audible and visual cues to aid the user in administration. This device has been shown to be safe and tolerable and to be bioequivalent to EpiPen 
(Dey Pharma LP, Napa, CA), with a similar serum peak concentration and total exposure [24].

Emergency action plans should also be available in the school setting where staff should be alerted to the child's allergies. At a minimum, the emergency action plan and epinephrine auto-injectors should be provided to and reviewed with school nurses and educators. In some instances, a Section 504 plan or individualized education program (IEP) may be necessary to promote safety in the school environment. Epinephrine should be quickly accessible in a school emergency, and staff should be adequately trained in medication delivery. Notably, federal legislation was signed in November 2013 to encourage states to adopt laws requiring schools to have "stock" epinephrine auto-injectors available to students who either have their first food reaction in the school setting or who have not yet been provided an auto-injector by their physician. Thus far, approximately 20 states have adopted such laws, while many other states are in the process of considering such legislation. New guidelines have been published by the Centers for Disease Control and Prevention to aid schools and early care and education programs in the management of children with food allergy [25]. The wearing of medical identification jewelry when children are outside of the home can alert strangers to the child's allergy in emergency situations.

Regular consultation with an allergy specialist is recommended yearly in early childhood as tolerance to some food allergens may be achieved. Milk, egg, soy and wheat are more commonly outgrown though resolution may not occur until adolescence [26-28]. At these visits, specialists review accidental ingestions, discuss current avoidance, perform any necessary follow-up testing and update emergency care plans. It is critical to update dosages of both antihistamines and epinephrine auto-injectors in the emergency action plan as these weight-based doses will change over time in growing children. Review of proper use of the chosen auto-injector is also suggested. A drop or steady decrease over time in food-specific IgE may be indicative of achievement of tolerance. Should the allergist suspect that tolerance to a food allergen has been achieved based on the predictive value of testing and absence of recent reactions with accidental ingestions, oral challenge to the food allergen in the clinic or hospital setting may be undertaken. A work group report thoroughly outlines appropriate conduct of oral food challenges [29]. Oral food challenges have been determined to be safe when performed with personnel trained in the management of anaphylaxis, with most children having relatively mild symptoms and few having lower airway symptoms $[30,31]$.

It is important to note that in some cases strict avoidance of food allergens may not always be advised. In recent years, attention has come to subsets of children with milk and egg allergy who can tolerate the food allergen when it is extensively heated. Early studies of baked milk and egg tolerance found 75 and $70 \%$ of enrolled children with allergy to milk and egg, respectively, were able to tolerate extensively heated items in an initial oral challenge [32, 33]. Previously, it was proposed that heating of these food items led to denaturation of conformational protein epitopes so that they were no longer recognized by $\operatorname{IgE}$ antibodies. However, the true mechanism of this tolerance has not been elucidated. Murine models have shown that extensively heating egg did not completely destroy epitopes recognized by $\mathrm{IgE}$ antibodies for egg-allergic children, yet altered degradation and absorption of the egg protein within the gastrointestinal tract was associated with decreased allergenicity in vivo [34]. Not only does this liberalization of avoidance improve quality of life by allowing for inclusion of a new variety of food products into the child's diet, but data also suggest that continued ingestion of these items accelerates tolerance of the unheated or lightly cooked milk or egg $[35,36]$.

\section{Oral Immunotherapy and Other Future Treatments for Food Allergy}

In the past 15 years, the most actively studied potential treatment for food allergy has been oral immunotherapy (OIT). Interestingly, the first report of successful OIT for egg allergy was published in 1908 [37]. Until 1998, little had been studied in this area. In 1998, Patriarca et al. described desensitizing a small cohort of children with food allergy [38]. Since then, there have been multiple studies of OIT for a variety of foods including peanut, milk and egg. Preliminary evidence for OIT is promising, with $50-75 \%$ of study participants tolerating an increased amount of food after treatment [39]. However, few trials have been performed in patients who have had oral challenges confirming their allergy prior to initiating OIT. In addition, there is lack of clarity about the safety and longterm efficacy of the treatment. Approximately 10-20\% of patients studied have withdrawn from studies because of adverse reactions, and another 10-20\% were only partially desensitized. Many patients have reactions during the escalation phase of therapy [40-42]. Reactions range from mild discomfort to severe reactions requiring treatment and withdrawal from the studies. Gastrointestinal symptoms are common, and several studies have noted the development of eosinophilic esophagitis in OIT patients [43-46]. To date, there have been no life-threatening reactions or deaths during OIT trials. The short-term efficacy of OIT has been shown; however, it is not clear whether desensitization will lead to tolerance. Tolerance occurs if the patient is able to stop oral intake of the food for a specified length of time 
and later pass an oral challenge [39]. The practice parameter on immunotherapy, created by a joint task force representing the American Academy of Allergy, Asthma and Immunology, The American College of Allergy, Asthma and Immunology and the Joint Council of Allergy, Asthma and Immunology, concludes that "the safety and efficacy of oral and sublingual immunotherapy for food hypersensitivity is currently investigational" [47•]. Although published studies regarding OIT are creating excitement among food allergy providers and patients, the current evidence does not support its introduction into clinical practice until current trials have been completed and regulatory body approval (i.e., the FDA) obtained.

\section{Conclusion}

Establishing the diagnosis of food allergy is primarily guided by a careful medical history in which typical IgEmediated clinical manifestations are reported to occur in a time frame of minutes to a few hours. Subsequent testing is performed to document the presence and concentration of sIgE to the suspected food. Skin prick tests and oral food challenges are not practical in a primary care setting, but in vitro tests for $\operatorname{sIgE}$ can easily be obtained. Screening panels should not be performed as they can lead to needless dietary restriction. With the recent availability of CRD testing, CRD may be used adjunctively with SIgE to assess the likelihood of clinical reactivity to peanut in order to provide anticipatory guidance to patients about future allergic reactions. Principles of management are beginning to evolve away from complete dietary avoidance for certain foods, such as milk and egg, for which it appears that ingestion of baked forms may accelerate development of tolerance in some individuals. New treatments are being actively studied and oral, sublingual and epicutaneous forms of allergen immunotherapy hold promise as future therapies.

Disclosure Rachel G. Robison, Melanie M. Makhija and Jacqueline A. Pongracic declare that they have no conflict of interest.

Human and Animal Rights and Informed Consent This article does not contain any studies with human or animal subjects performed by any of the authors.

\section{References}

Papers of particular interest, published recently, have been highlighted as:

- Of importance

•- Of major importance
1. • Boyce JA, Assa'ad A, Burks AW, Jones SM, Sampson HA, Wood RA et al. Guidelines for the diagnosis and management of food allergy in the United States: report of the NIAID-sponsored expert panel. J Allergy Clin Immunol. 2010;126(6 Suppl):S1-58. doi:10.1016/j.jaci.2010.10.007. These guidelines published by the NIAID represent the first set of recommendations on "best practices" for the diagnosis and management of food allergy and are a must-read for any practitioner who treats or manages children with food allergies.

2. Bock SA, Lee WY, Remigio L, Holst A, May CD. Appraisal of skin tests with food extracts for diagnosis of food hypersensitivity. Clin Allergy. 1978;8(6):559-64.

3. Wang J, Godbold JH, Sampson HA. Correlation of serum allergy (IgE) tests performed by different assay systems. J Allergy Clin Immunol. 2008;121(5):1219-24. doi:10.1016/j.jaci.2007.12.1150.

4. Sampson HA, Ho DG. Relationship between food-specific IgE concentrations and the risk of positive food challenges in children and adolescents. J Allergy Clin Immunol. 1997;100(4):444-51.

5. Sampson HA. Utility of food-specific $\operatorname{IgE}$ concentrations in predicting symptomatic food allergy. J Allergy Clin Immunol. 2001;107(5):891-6. doi:10.1067/mai.2001.114708.

6. Celik-Bilgili S, Mehl A, Verstege A, Staden U, Nocon M, Beyer $\mathrm{K}$, et al. The predictive value of specific immunoglobulin $\mathrm{E}$ levels in serum for the outcome of oral food challenges. Clin Exp Allergy. 2005;35(3):268-73. doi:10.1111/j.1365-2222.2005. 02150.x.

7. Perry TT, Matsui EC, Kay Conover-Walker M, Wood RA. The relationship of allergen-specific IgE levels and oral food challenge outcome. J Allergy Clin Immunol. 2004;114(1):144-9. doi:10.1016/j.jaci.2004.04.009.

8. Nicolaou N, Murray C, Belgrave D, Poorafshar M, Simpson A, Custovic A. Quantification of specific IgE to whole peanut extract and peanut components in prediction of peanut allergy. J Allergy Clin Immunol. 2011;127(3):684-5. doi:10.1016/j.jaci.2010.12. 012 .

9. Ebisawa M, Moverare R, Sato S, Maruyama N, Borres MP, Komata T. Measurement of Ara h 1-, 2-, and 3-specific IgE antibodies is useful in diagnosis of peanut allergy in Japanese children. Pediatr Allergy Immunol. 2012;23(6):573-81. doi:10. 1111/j.1399-3038.2012.01332.x.

10. Asarnoj A, Nilsson C, Lidholm J, Glaumann S, Ostblom E, Hedlin $\mathrm{G}$, et al. Peanut component Ara h 8 sensitization and tolerance to peanut. J Allergy Clin Immunol. 2012;130(2):468-72. doi:10.1016/ j.jaci.2012.05.019.

11. - Lieberman JA, Glaumann S, Batelson S, Borres MP, Sampson $\mathrm{HA}$, Nilsson C. The utility of peanut components in the diagnosis of IgE-mediated peanut allergy among distinct populations. J Allergy Clin Immunol Pract. 2013;1(1):75-82. doi:10.1016/j. jaip.2012.11.002. An in-depth discussion of component-resolved diagnostics testing for IgE-mediated peanut allergy.

12. - Simons FE, Ardusso LR, Bilo MB, El-Gamal YM, Ledford DK, Ring $\mathrm{J}$ et al. World allergy organization guidelines for the assessment and management of anaphylaxis. World Allergy Org J. 2011;4(2):13-37. doi:10.1097/WOX.0b013e318211496c. This set of guidelines provides a comprehensive analysis of the literature and current recommendations for the treatment of anaphylaxis.

13. de Silva IL, Mehr SS, Tey D, Tang ML. Paediatric anaphylaxis: a 5 year retrospective review. Allergy. 2008;63(8):1071-6. doi:10. 1111/j.1398-9995.2008.01719.x.

14. Grabenhenrich L, Hompes S, Gough H, Rueff F, Scherer K, Pfohler $\mathrm{C}$, et al. Implementation of anaphylaxis management guidelines: a register-based study. PLoS ONE. 2012;7(5):e35778. doi:10.1371/journal.pone.0035778.

15. Jarvinen KM, Sicherer SH, Sampson HA, Nowak-Wegrzyn A. Use of multiple doses of epinephrine in food-induced anaphylaxis 
in children. J Allergy Clin Immunol. 2008;122(1):133-8. doi:10. 1016/j.jaci.2008.04.031.

16. Lee JM, Greenes DS. Biphasic anaphylactic reactions in pediatrics. Pediatrics. 2000;106(4):762-6.

17. Tole JW, Lieberman P. Biphasic anaphylaxis: review of incidence, clinical predictors, and observation recommendations. Immunol Allergy Clin North Am. 2007;27(2):309-26, viii. doi:10.1016/j.iac.2007.03.011.

18. Choo KJ, Simons FE, Sheikh A. Glucocorticoids for the treatment of anaphylaxis. Cochrane Database Syst Rev. 2012;4:CD007596. doi:10.1002/14651858.CD007596.pub3.

19. Fleischer DM, Perry TT, Atkins D, Wood RA, Burks AW, Jones $\mathrm{SM}$, et al. Allergic reactions to foods in preschool-aged children in a prospective observational food allergy study. Pediatrics. 2012;130(1):e25-32. doi:10.1542/peds.2011-1762.

20. Nguyen-Luu NU, Ben-Shoshan M, Alizadehfar R, Joseph L, Harada L, Allen M, et al. Inadvertent exposures in children with peanut allergy. Pediatr Allergy Immunol. 2012;23(2):133-9. doi:10.1111/j.1399-3038.2011.01235.x.

21. Ford LS, Taylor SL, Pacenza R, Niemann LM, Lambrecht DM, Sicherer SH. Food allergen advisory labeling and product contamination with egg, milk, and peanut. J Allergy Clin Immunol. 2010;126(2):384-5. doi:10.1016/j.jaci.2010.05.034.

22. Sicherer SH, Forman JA, Noone SA. Use assessment of selfadministered epinephrine among food-allergic children and pediatricians. Pediatrics. 2000;105(2):359-62.

23. Segal N, Garty BZ, Hoffer V, Levy Y. Effect of instruction on the ability to use a self-administered epinephrine injector. Israel Med Assoc J. 2012;14(1):14-7.

24. Edwards ES, Gunn R, Simons ER, Carr K, Chinchilli VM, Painter $\mathrm{G}$, et al. Bioavailability of epinephrine from Auvi-Q compared with EpiPen. Ann Allergy Asthma Immunol. 2013;111(2):132-7. doi:10.1016/j.anai.2013.06.002.

25. Centers for Disease Control and Prevention. Voluntary guidelines for managing food allergies in schools and early care and education programs. Washington, DC: US Department of Health and Human Services; 2013.

26. Savage JH, Matsui EC, Skripak JM, Wood RA. The natural history of egg allergy. J Allergy Clin Immunol. 2007;120(6):1413-7. doi:10.1016/j.jaci.2007.09.040.

27. Skripak JM, Matsui EC, Mudd K, Wood RA. The natural history of IgE-mediated cow's milk allergy. J Allergy Clin Immunol. 2007;120(5):1172-7. doi:10.1016/j.jaci.2007.08.023.

28. Keet CA, Matsui EC, Dhillon G, Lenehan P, Paterakis M, Wood RA. The natural history of wheat allergy. Ann Allergy Asthma Immunol. 2009;102(5):410-5. doi:10.1016/s1081-1206(10)60513-3.

29. Nowak-Wegrzyn A, Assa'ad AH, Bahna SL, Bock SA, Sicherer SH, Teuber SS. Work Group report: oral food challenge testing. J Allergy Clin Immunol. 2009;123(6 Suppl):S365-83. doi:10. 1016/j.jaci.2009.03.042.

30. Jarvinen KM, Amalanayagam S, Shreffler WG, Noone S, Sicherer SH, Sampson HA, et al. Epinephrine treatment is infrequent and biphasic reactions are rare in food-induced reactions during oral food challenges in children. J Allergy Clin Immunol. 2009;124(6):1267-72. doi:10.1016/j.jaci.2009.10.006.

31. Calvani M, Berti I, Fiocchi A, Galli E, Giorgio V, Martelli A, et al. Oral food challenge: safety, adherence to guidelines and predictive value of skin prick testing. Pediatr Allergy Immunol. 2012;23(8):755-61. doi:10.1111/pai.12016.

32. Nowak-Wegrzyn A, Bloom KA, Sicherer SH, Shreffler WG, Noone $\mathrm{S}$, Wanich $\mathrm{N}$ et al. Tolerance to extensively heated milk in children with cow's milk allergy. J Allergy Clin Immunol. 2008;122(2):342-7, 7 e1-2. doi:10.1016/j.jaci.2008.05.043.

33. Lemon-Mule H, Sampson HA, Sicherer SH, Shreffler WG, Noone S, Nowak-Wegrzyn A. Immunologic changes in children with egg allergy ingesting extensively heated egg. J Allergy Clin Immunol. 2008;122(5):977-83 e1. doi:10.1016/j.jaci.2008.09. 007.

34. Martos G, Lopez-Exposito I, Bencharitiwong R, Berin MC, Nowak-Wegrzyn A. Mechanisms underlying differential food allergy response to heated egg. J Allergy Clin Immunol. 2011;127(4):990-7 e1-2. doi:10.1016/j.jaci.2011.01.057.

35. Kim JS, Nowak-Wegrzyn A, Sicherer SH, Noone S, Moshier EL, Sampson HA. Dietary baked milk accelerates the resolution of cow's milk allergy in children. J Allergy Clin Immunol. 2011;128(1):125-31 e2. doi:10.1016/j.jaci.2011.04.036.

36. Leonard SA, Sampson HA, Sicherer SH, Noone S, Moshier EL, Godbold J et al. Dietary baked egg accelerates resolution of egg allergy in children. J Allergy Clin Immunol. 2012;130(2):473-80 e1. doi:10.1016/j.jaci.2012.06.006.

37. Schofield A. A case of egg poisoning. Lancet. 1908;1:716.

38. Patriarca G, Schiavino D, Nucera E, Schinco G, Milani A, Gasbarrini GB. Food allergy in children: results of a standardized protocol for oral desensitization. Hepatogastroenterology. 1998;45(19):52-8.

39. Khoriaty E, Umetsu DT. Oral immunotherapy for food allergy: towards a new horizon. Allergy Asthma Immunol Res. 2013;5(1): 3-15. doi:10.4168/aair.2013.5.1.3.

40. Meglio P, Bartone E, Plantamura M, Arabito E, Giampietro PG. A protocol for oral desensitization in children with IgE-mediated cow's milk allergy. Allergy. 2004;59(9):980-7. doi:10.1111/j. 1398-9995.2004.00542.x.

41. Longo G, Barbi E, Berti I, Meneghetti R, Pittalis A, Ronfani L, et al. Specific oral tolerance induction in children with very severe cow's milk-induced reactions. J Allergy Clin Immunol. 2008;121(2):343-7. doi:10.1016/j.jaci.2007.10.029.

42. Keet CA, Frischmeyer-Guerrerio PA, Thyagarajan A, Schroeder JT, Hamilton RG, Boden S et al. The safety and efficacy of sublingual and oral immunotherapy for milk allergy. J Allergy Clin Immunol. 2012;129(2):448-55, 55 e1-5. doi:10.1016/j.jaci. 2011.10.023.

43. Ridolo E, De Angelis GL, Dall'aglio P. Eosinophilic esophagitis after specific oral tolerance induction for egg protein. Annals Allergy Asthma Immunol. 2011;106(1):73-4. doi:10.1016/j.anai. 2010.10.010

44. Sanchez-Garcia S, Rodriguez Del Rio P, Escudero C, MartinezGomez MJ, Ibanez MD. Possible eosinophilic esophagitis induced by milk oral immunotherapy. J Allergy Clin Immunol. 2012;129(4):1155-7. doi:10.1016/j.jaci.2011.11.042.

45. Wasserman RL, Sugerman RW, Mireku-Akomeah N, Gallucci AR, Pence DM, Long NA. Peanut oral immunotherapy (OIT) of food allergy (FA) carries a significant risk of eosinophilic esophagitis (EoE). J Allergy Clin Immunol. 2011;127(2):AB28.

46. Stein ML, Levy MB, Goldberg MR, Hermann G, Broide E, Elizur A et al. Classification, prevalence and outcomes of non-IgE mediated reactions to oral food immunotherapy. J Allergy Clin Immunol. 2012;129(2):AB29.

47. - Sampson HA. Peanut oral immunotherapy: is it ready for clinical practice? J Allergy Clin Immunol Pract. 2013;1(1):15-21. doi:10.1016/j.jaip.2012.10.009. This is a review of all studies and trials of peanut oral immunotherapy to date with a discussion of the pros and cons of OIT use in practice. 